\title{
Business Planning in Biobanking: How to Implement a Tool for Sustainability
}

\author{
Mirella Ciaburri1,2 Mariarosaria Napolitano,2 and Elena Bravo²
}

Worldwide, the sustainability of public health systems is challenged by the increasing number and cost of personalized therapies. Quality biological samples stored in biobanks are essential for the provision of appropriate health services and also act as a reservoir for the development of precision medicine and biotechnological innovation. Economic sustainability is a crucial factor in the maintenance of biobanking activities. Traditionally, management of biobanking is performed by health researchers and/or clinicians whose knowledge of economic issues is inadequate. On the other hand, familiarity with financial instruments used by economists is not often accompanied by a consolidated understanding of biobanking features. This article aims to be a guide for the implementation of business plans in biobanking and proposes models for the facilitation of their preparation, thus contributing to recognition of the importance of efficient management of resources of public health services.

Keywords: biobanks, bioresource, business plan, cost analysis, sustainability

\section{Introduction}

$\mathrm{T}$ HE ECONOMIC AND SOCIAL importance of biobanking is growing due to the rapid acceleration of biotechnology ${ }^{1}$ and to the parallel augmented impact of human samples in translational medicine. ${ }^{2-4}$ Notwithstanding the increasing interest of public and private sectors, a major unresolved question is still the economic sustainability of both individual collections and of biobanking complex infrastructures, ${ }^{5,6}$ of which the main products are the human samples that are not commercial goods. ${ }^{7}$ Thus, the development of economically sustainable models for biobanking is a matter of debate, and different models of economic revenues based on different cost recovery processes have been proposed. ${ }^{4,5,8}$

In the private sector, activities are primarily approached from an economic point of view, using economic tools to assess the feasibility of the operation and its sustainability in the future. Thus, there is a long-lasting cultural tradition in planning the business prospectively and in using economic tools such as the Business Plan (BP) and quality implementation systems to both increase quality of the products/services and decrease operating costs. These instruments are fundamental to allow economic sustainability and success of the initiatives. The most important instrument that is used in evaluating the project is the $\mathrm{BP} .^{9-11}$ The BP must be organized according to a strict scheme, ${ }^{9,12}$ which defines all the contents of the project that will be achieved in the long term, and its major goal is to show that the company will not only be able to survive in the future but will also generate positive results.

Traditionally, on the other hand, biobanks, especially when embedded in public health policies, have not been recognized as individual economic units, and biobanking activities have been managed with little attention to the breakdown of expenses and possible revenues. For instance, clinical biobanks originating in their home structure (i.e., hospital and healthcare institutes) and the economic value of their activities were not analyzed separately. Thus, their costs were included in the total financial statements of the home institute, and the sustainability of these structures was a hidden cost of the public healthcare system. In the public sector, most of the services were provided with a major focus on the political and social needs of health services, with less attention paid to the longterm sustainability of services offered and insufficient development and application of key performance indicators. ${ }^{13}$

In parallel, population and clinical biobanks ${ }^{14,15}$ accumulated a huge number of valuable biospecimens and data, which were collected to respond to the specific scientific aims of clinical and/or epidemiological studies. However, such projects and collections did not make any prospective (economic) plans for the maintenance of their bioresources.

Basically, scientists have the know-how necessary to manage a biobank, but their familiarity with economic tools

\footnotetext{
${ }^{1}$ Department of Management, University LUISS Guido Carli, Rome, Italy.

${ }^{2}$ Departments of Haematology, Oncology and Molecular Medicine, Istituto Superiore di Sanità, Rome, Italy.
}

(C) Mirella Ciaburri et al., 2017; Published by Mary Ann Liebert, Inc. This Open Access article is distributed under the terms of the Creative Commons Attribution Noncommercial License (http://creativecommons.org/licenses/by-nc/4.0/) which permits any noncommercial use, distribution, and reproduction in any medium, provided the original author(s) and the source are credited. 
is limited. Traditionally, management of public health services was not multidisciplinary, scientific work was not generally supported by economists, and, in several cases in the public sector, there is a general lack of the cultural background required for economic planning and for the use of appropriate tools designed for managing sustainability. Thus, this article aims to increase awareness of the importance of the use of proper tools for the management of economic sustainability of biobanks and to implement the use of economic tools, which are essential for correct management of such infrastructures. ${ }^{16}$

We aim to depict features of the BP and to provide a practical basic guide to its development for biobankers, scientists, managers, and stakeholders. Although this article is mainly focused on human samples and related biobanks, the principles and ideas reported may be applied to any other structure dedicated to an organized storage of biomaterials and their associated data for research purposes.

\section{Methodology for Implementation}

In this article, we present the principles, the structure, and the model of a BP for biobanking, according to principles drafted by Stutely ${ }^{9}$ in 2005 . The sections of a typical BP are as follows:

(1) Cover

(2) Entrepreneur and organization data

(3) Project description and mission

(4) Market analysis

(5) Marketing strategies

(6) Organizational structure

(7) Economic and financial provisions

(7.1) Costs

(7.2) Funds

(7.3) Revenues

The BP is generally structured on a medium to long time horizon, usually no longer than 5 years ${ }^{17}$ and possibly with a greater level of detail for the initial years.

In the following sections, the different parts of a typical $\mathrm{BP}$ are analyzed. Each outlines a simplified guide for the document, supplying information either in general terms and/or for specific issues related to biobanking, with a final summary of the main points, which need to be included.

\section{Cover}

The $\operatorname{cover}^{10}$ represents the opening page of each BP. It contains the name of the project or of the firm and an indication of the time horizon to be considered in the following pages.

The cover of a biobank BP must include this same information. In addition, if available, it should indicate the unique identifier of the biobank, which can be used reliably to readily recognize and trace on the Web any activity of the biobank. $^{18}$

\section{Entrepreneur and organization data}

The purpose of this section is to provide general data on the activities to be performed and includes a presentation of the entrepreneur and a description of the most important organizational data.

Entrepreneur presentation. In a general BP, this section has a descriptive function and outlines the personality of the entrepreneur and of the founder. ${ }^{12}$ Personal data, professional profile, past experiences, and competencies that may be relevant for the covered role should be reported. In some cases, that is, when the business has been recently created, the entrepreneur may also be the founder of the business. The founder is the person who started the business using his own capital or that raised from other financers.

For a biobank, the identification of the founder and the entrepreneur requires an analysis of the biobank structure and origin. If the biobank originated from collections from a specific project, the founder is identified as the principal investigator of that project. Other biobanks originate from private or public/private foundation initiatives as a response to demands from investigators and funded by disease-focused foundations, advocacy organizations, and/or commercial entities who want to develop new therapies and diagnostic tools for the disease. ${ }^{19}$ In this case, the founder(s) and source of capital are generally well defined and the identification of funder and entrepreneur is facilitated. ${ }^{20}$

In most cases, however, identification of the founder of a biobanking project is more difficult. Sometimes, with a largescale infrastructure, the biobank or the biological resource center $^{21}$ manages several types of biospecimen collections derived from diverse studies, which may or may not still have a direct link with the original principal investigator. Another common case is a disease biobank that originated from healthcare activities set in a hospital/healthcare institution. In the vast majority of these, with very few exceptions, it is difficult to identify the typical entrepreneur depicted by the BP. This role is then assigned to the Senior Manager, who is designated as responsible for the biobank. According to the Organization for Economic Co-operation and Development (OECD) Best Practice Guidelines for Biological Resource Centres, ${ }^{22}$ the Senior Manager of the biobank must be qualified to make decisions on ethical, scientific, and managerial issues and may also delegate responsibilities to qualified staff.

The Senior Manager has, in fact, the primary responsibility for the implementation of biobank policies and for decisions on ethical, scientific, and managerial issues. He/she may also delegate individual responsibility and the corresponding authority to suitably qualified members of the staff. The senior management is also in charge of ensuring appropriate administration, monitoring, updating of quality systems, and internal compliance with biosecurity by appointing, respectively, the Quality Manager and the Biosecurity Officer. ${ }^{22}$

In such a case, this section of the BP reports a brief profile of the Senior Manager to highlight how their experience and competencies fulfill the requirements needed to manage a biobank.

Organization data. For a generic firm, this subsection of a BP includes general information, such as the type of products the firm provides to its customers, the industry in which it operates, the date of founding, the size in terms of number of employees, and other elements useful to define the business.

All the elements listed above are considered in the context of a biobank.

A simplified panel of information to be included is indicated below:

- The type of biobank (population, clinical, genetic, multispecialty, biodiversity, institutional, cell, microbiologic, etc.).

- The origin of the samples stored (i.e., research, diagnosis, therapeutics, outpatient, germs, environment). 
- The number of samples (as derived from each individual organism) stored.

- The kind of biospecimens stored (i.e., blood, urine, solid tissues, biological fluids, microorganism, infectious agent) and/or their derivatives (i.e., buffy coat, plasma, serum, DNA, RNA).

- Biobank products available according to the adopted sharing policy (biospecimen and/or derivatives).

- Provision of annual sample management (see also the Economic and financial provisions section).

In summary, the section-Entrepreneur and organization data-should report a short professional portrait of the person identified as the entrepreneur and the organization data related to the type and/or services offered by the biobank and general policies adopted for their use.

\section{Project description and mission}

The aim of the third part of a BP is to provide a detailed rationale for the project. For a biobank, this will lay out the objectives to be reached through the implementation/maintenance of biobanking activities.

Project description. For a generic firm, this section must identify the product/service in all its features, together with the technology used, the existing independent certification, the patents owned, and the know-how applied. These elements are fundamental to demonstrate that the knowledge needed for proper management of activities of the project is available.

For a biobank, the description of the project defines in detail the features of the samples stored, including the reason for their collection and the way it was done. Products of the biobank can primarily consist of data, samples and associated data, and services offered for any type of activity by the biobank. It is useful to define the biological nature of available samples, such as organism, infectious agent, tissue, or biomaterial derivative (serum, cells, DNA, RNA; proteins, etc.), as well as the state of the sample (i.e., dry, frozen) and storage conditions (temperature, container, quantity for aliquot, etc). The inclusion of a brief history of the biobank is appropriate.

For long-lasting biobanks, the history of the biobank may be complex because of the variable origin and development of the infrastructure. If different collections are stored in the infrastructure, the description in this section of the BP will include a list of completed and ongoing collections of the sample stored. The administrative and functional relationships between the Senior Manager and the scientists responsible for each collection must be reported. Ongoing prospective collection will be clearly indicated. In this section, inclusion of a table showing a list of biospecimen collections managed by the biobank may also be useful. This table should give the title, mission, starting date of collection, actual state of the project (completed/ongoing), ethical, scientific, and legal staff responsible for each collection, and their relationship with the Senior Manager of the infrastructure.

SWOT analysis. An integral part of any project description is the SWOT analysis ${ }^{23}$ designed to assess its strengths, weaknesses, opportunities, and threats. The first two elements (strengths and weaknesses) are internal factors, while the last two elements (opportunities and threats) are external factors.

The strengths of a biobank may derive from its quality, the number of samples and specific features of the material, and simplified procedures for access to samples. Quality (i.e., adherence to standard quality principles and procedures, certification, accreditation) and richness of the data associated with the sample represent a strength for the biobank. In particular, biobanks that implement an international, recognized quality management system (QMS) are regarded as preferential partners for development of market applications. The Organization for Standardization (ISO) is now setting requirements for bioresources for research and market use using the working group, biobanking, established in the Technical Committee (TC) 276 Biotechnology. ${ }^{24}$

The clinical origin, detailed information on the preanalytical procedures, the scope of the study, its geographical origin, inclusion criteria of high-efficiency organization, reliability of the institution, certification, the extent of available knowledge associated with the samples, rare derivatives, laboratory equipment, and storage technology are important elements, which determine uniqueness or rarity of material. Further strengths may come from the policy adopted and capability of offering efficient services (i.e., an easy and clear access policy, affordable service costs, efficient delivery systems, speed, and security of data transfer).

So far, one of the most common recognized weaknesses of biobanking is the difficulty of covering the total cost of the infrastructure independently of the economic model adopted $^{4,8,20,25}$ and the scarce use of bioresources. ${ }^{18,26}$ In addition, weakness may occur when the destiny of samples collected within a funded project is undetermined when the project ends.

Opportunities may refer to the possibility to develop and become a center of territorial (institution; region; national, global) reference for the management of samples in the specific area of activity, to join networks or merge with other centers, and to implement further biobanking services to offer to public and private sectors.

Threats. Disaster and the lack of contingency plans are some of the main threats that biobank may face. ${ }^{27,28}$

Natural, human, or technological accidents may threaten the biobank. ${ }^{29}$ It is advisable to add to this section a part dedicated to alternative strategies, in which additional costs for risk assessment, mitigation, and contingency planning are considered and specifically adapted for the location and environment of the biobank.

Financial failure deriving from decrease/loss of public funding or charity support, bankruptcy, closure of the host institution, or a change in institutional policy involving disposal are other possible dangers.

Additional threats may derive from ethical-legal issues such as massive withdrawal of consent, for example, due to the social impact of a news story causing public distrust.

The mission. The definition ${ }^{30}$ of the mission, that is, the statement of purpose of the organization is essential in any BP. The mission, generally stated in a few lines (mission statement), justifies the existence of the firm and guides the actions of the organization. Although the mission is a facultative field of the BP, careful drafting is highly recommended both for firms and biobanks. ${ }^{30,31}$

The mission targets and identifies the major scope of the biobank and it indicates why the biobank, even if embedded in a more complex institution, exists and needs to be maintained.

To summarize, the Project description and mission section should report the mission together with a description of the rationale and of the history of the biobank accompanied by a detailed description of products and services, policies, and personnel relationships. 
SWOT analysis and alternative strategies are an integral part of this section.

Taking into account the quantity and importance of the information to be reported, the use of tables is highly recommended.

\section{Market analysis}

The purpose of this section is to identify and outline relationships with the stakeholders. Thus, this section of a BP shifts the focus to the external environment.

For a generic firm, this analysis aims to define the trends related to supply and demand inside the industry, to identify the competitors, and above all to indicate the stakeholders of the firm.

For a biobank, it is important to analyze the social, cultural, and political environment in which the infrastructure is integrated to identify and examine the stakeholders involved. A sort of identity kit of the different stakeholders is required to evaluate which of their interests the biobank has to protect and which of them are able to influence the biobank. According to the stakeholders' theory, ${ }^{32}$ all the processes developed by an organization have to satisfy different stakeholders' expectations. $^{33,34}$

In keeping with the different aims, structure, and organization, each biobank should identify the interested parties and address market activity that satisfies their expectations. The analysis of the type of biospecimens and of the services offered by the most competitive biobanks favors identification of additional/alternative activities to improve the response to stakeholders' requests.

The most common stakeholder categories include the following:

\section{- Donors and/or patients}

Persons who give samples to biobanks are important stakeholders ${ }^{19,33,35}$; however, their role and involvement may vary markedly among bioresource centers. Donors are the engine of the population biobanks and are represented by all the people who accept the invitation to participate in a research/epidemiological program. The involvement of citizens is generally dependent on institution/biobank reliability and trust in the use of their specimens for research. ${ }^{35,36}$

Disease-oriented biobanks collect data and samples from patients and their involvement is becoming more and more valuable. The activities of patient organizations ${ }^{17,22}$ reflect the capability of patients and donors to advocate their interests and to favor biobanking policies that better safeguard their rights. Nowadays, in fact, several disease-focused foundations and patient advocacy organizations cover niche fields and are sustaining biobanks. This model represents a financial model for the operational sustainability of biobanking. 17

- Researchers

Public and private researchers interested in using samples and/or associated data for research purposes are fundamental stakeholders for biobanking. They can be considered the engine of the infrastructure because they are also the major providers of samples and play an important role in establishing and maintaining bioresources. Their capability to act as both providers and users of samples is crucially dependent on the recognition of the impact of biobanking activities. ${ }^{18}$

- Private and public sectors

Several biotechnologies need bioresources to develop applications in the performance and capabilities of many different sectors, such as healthcare and medicine, agricultural production, and industrial production. ${ }^{1}$ Thus, biobanks are a precious source of samples and data for the development of commercial products in both public and private sectors. However, several issues related to PublicPrivate Partnerships are still under debate. ${ }^{17,20}$ This section of the BP must define the relationship of the biobank to industrial sectors and its policy toward either private or public partners.

- Public institution/bodies

Public sectors can be variously represented by the State or the region/district or hosting public institution. They are important stakeholders as they define current legislation. In particular, they are in charge of the accreditation of the institution and also provide partial or total funding of the biobank.

- The staff

This category of stakeholders refers to both personnel reported in the organizational chart (see the Organizational structure section) and the external personnel. Very often, the building and maintenance of bioresources require additional competencies (i.e., medical staff, pathologists, surgeons, epidemiologists, nurses) that are devoted to the external collection of samples and data. Taking account of the expectations of these stakeholders is a factor in the success of the project as most of this highly specialized work is performed on a voluntary basis and sometimes performed as an in-kind contribution.

- Financial supporters

Funders have to be included in the category of relevant stakeholders because they provide the biobank with the financial funds necessary for it to function (a detailed analysis of the financial supporters will be developed in the following section).

\section{- Network/partnership/consortium}

The partners in a network/consortium are also important stakeholders and analysis of the importance of hierarchical and complementary relationships is outlined in this section.

In summary, this section should include a simple and exhaustive stakeholder analysis. Each category of potential stakeholders has to be taken into consideration, and major attention has to be paid to categories that benefit from these activities as well as those that may contribute to the sustainability of the biobank.

\section{Marketing strategies}

For a generic firm, the marketing process is defined as a set of actions, which create a relationship with the customer, to keep the existing clients and acquire new ones. ${ }^{37,38}$ In this section of the BP, all the marketing strategies are defined to render the firm and its products recognizable to customers.

The marketing strategies (from advertising to packaging to market positioning) have the ultimate target of creating value for the firm offering the product to the customers. 
According to the defined budget and timescale, each firm operates different types of marketing and communication strategies, such as television or radio spots, the creation of a website dedicated to the single product or to the firm, roadside posters, newspaper advertising, flyers, and so on.

The market analysis (see the Market analysis section above) will indicate the best communication channel to meet the stakeholders' needs and the market strategies to be implemented to increase the trust of stakeholders and to attract more philanthropic donations. ${ }^{4}$ Thus, in this section, the biobank needs to underline the importance of access to samples through the participation of relevant research projects, collaboration with private sectors, and also to make available data on the use of biobank samples/data/ services. ${ }^{4,18}$ Future public funding and private partnerships will be more and more based on evaluation of the capability of the biobank to contribute to red biotech development.

The marketing strategies define the communication channels chosen to best inform the stakeholders and include flyers, leaflets, brochures, newspaper advertising, in loco information, television, or radio spots. The website, however, is the most useful channel to provide information related to the biobank, its mission, and the activities it performs. Marketing strategies may differ over the years as they may be dependent on the stage of development (i.e., setting, initial, upgrading) and/or changes in the adopted policies. Social networks, smart applications, cartoons, specific patient association communication, and dedicated forums are also becoming more commonly used.

In summary, the Marketing strategies section includes the approaches that will be put in place to inform the stakeholders and to advertise the biobank's activities.

\section{Organizational structure and governance model}

In any BP, this section comprises two main sections that are strictly related: the organizational structure and governance. The organizational structure includes a definition of the legal form. The governance model adopted is largely dependent on the activities performed and may be very heterogeneous. In this section, whatever model is adopted, bodies/committees and related activities should be clearly defined.

Organizational structure. A generic firm would usually adopt one of the following organizational structures ${ }^{39}$ :

- The functional structure, is a common type of organizational structure where all the activities are grouped together according to a common function (a function is a group of operations that are similar from a technical point of view). Classically, the employees are grouped hierarchically, managed through clear lines of management, and report ultimately to one senior person, and the firm divides departments by the functions performed. For example, the organization may be divided into smaller groups based on specialized functional areas, such as IT, finance, or marketing. ${ }^{40}$

- The divisional structure, where the units composing the firm are organized according to the output of the organization (products or services offered to customers). In other words, the divisional structure (or product structure) consists of self-contained divisions. A division is a collection of functions, which deliver a product. Employees who are responsible for certain market services or types of products are placed in divisional structure to increase their flexibility. Each division may also have their own departments such as marketing, sales, and engineering.

- The matrix structure, where we can find two lines of authority: as per functions and per outputs. This structure can combine the best of both separate structures. The matrix organization structure is usually defined as one where there are multiple reporting lines - that is, people/functions have more than one formal reference to report their activity.

Many types of matrix combined schema may be built and, generally, they are complex structures that are generally not adopted by small businesses.

Any of these organizational structures may be adopted and developed by a biobank. However, for biobanks where storage activity is associated with a heterogeneous set of analytical procedures, the divisional structure seems to be the one that best fits the scope because biobank products (high-quality samples and associated data) may be best delivered by strong inter-relationships between the different activities. Figure 1 shows a simplified example of the major differences between a functional and divisional structure that are applied to a biobank.

In the past, the legal form adopted by a biobank was rarely specified because in most cases, the biobank was part of a larger institution such as a hospital or a private/public research or care institute.

When the biobank is an independent organization, it often assumes the form of an association (i.e., http://biobanknetwork .telethon.it) or of a foundation (i.e., www.davincieuropean biobank.org/it/home/about-us/the-repository). In this case, the BP will refer to what is reported in the statute of the organization.

This subsection must be completed with the personnel organizational chart, which shows the human resources employed. The organizational chart reports the different executive and operative positions covered by the personnel, together with a brief description of their profiles.

Governance model. The governance model adopted by a generic firm must be included in this section of the BP. Depending on the host country, each firm can freely choose which model to use.

The most common models ${ }^{41}$ are as follows:

- The one-tier system, with one governing body responsible for management and control.

- The two-tier system, with two governing bodies, one responsible for management and the other for the control.

A large variety of governance models can be developed according to the complexity of the biobank. The governance should be determined by each biobank according to its organization, and other functions necessary to the biobank (i.e., bioinformatics, biosafety, engineers) may be covered by committees, personnel, or consultants. Defined functions and hierarchic positions must be reported in the governance schema and on the organizational chart (see the Organizational structure section) of the BP. The organizational chart must also show the composition of the committee(s), with a brief note on related function(s) and, possibly, requirements to cover the position. The decision-making level is generally covered by a Senior Manager and control functions by the Quality manager.

Other (i.e., Scientific, Ethics, Finance) committees are often implemented by highly complex biobanks or networks. The organizational chart is required to be publicly displayed in a position where all employees have direct access to it. 

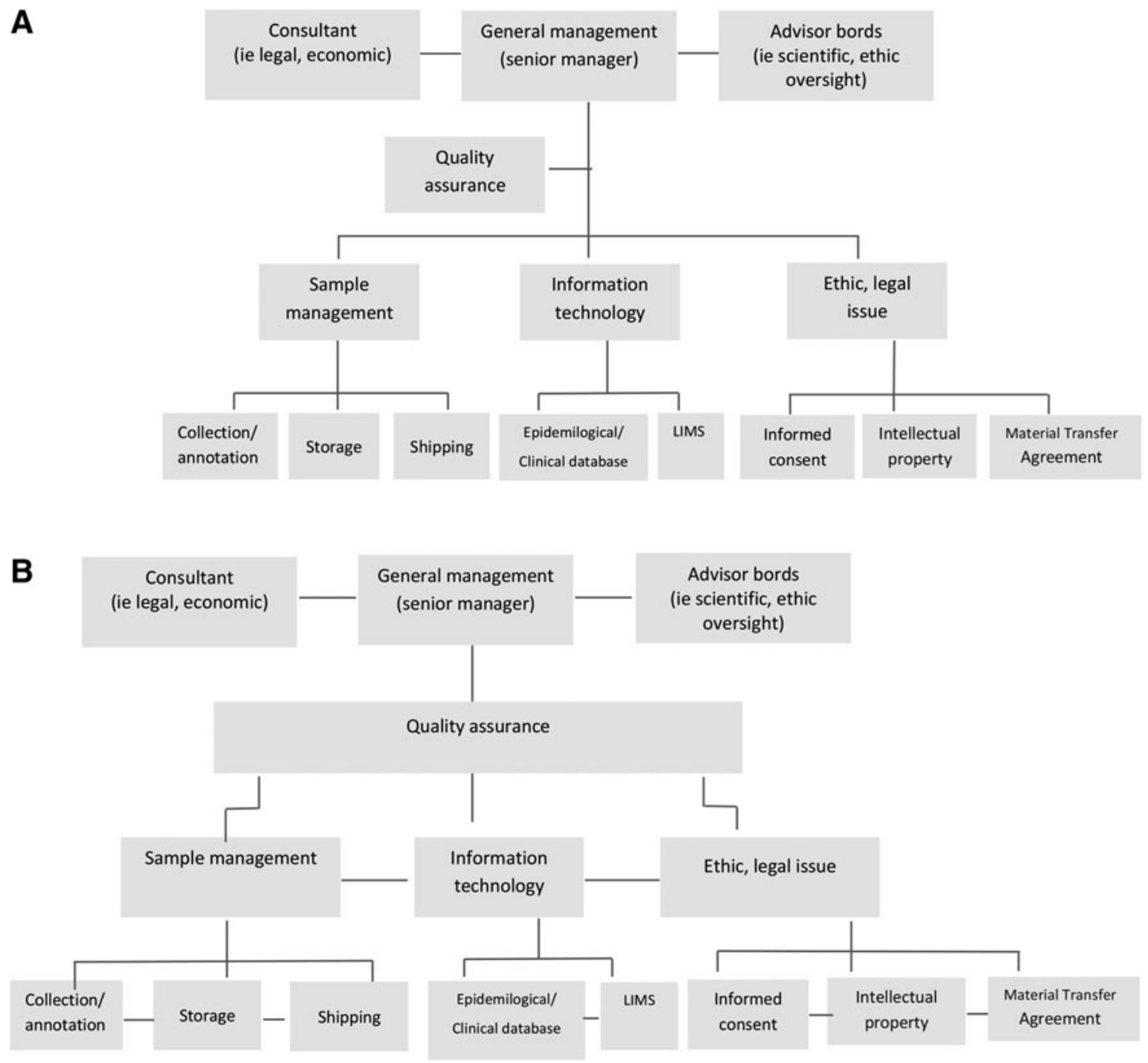

FIG. 1. Organizational structure. The figure shows simplified schemas of functional (A) and divisional (B) organizational structure applied to a biobank.

In summary, these sections report the organization and related authority that is responsible for all the different activities as well as the hierarchic interrelationships between them. For each biobank, the organization structure and steering/governance committee should be constructed so that the aims and activities ensure efficiency in the processes and services performed.

\section{Economic and financial provisions}

For a generic firm, as well as for a biobank, the economic and financial analysis aims to present the economic and financial structure of the project. In this article, this section is focused on the biobank.

The economic and financial provisions can be divided in three parts, the first related to costs and the second and the third to funds and to revenues, respectively.

For research biobanks, this part is often the most difficult to complete, as there is a general and recognized absence of data, due to the tradition of working in this sector without a $\mathrm{BP}{ }^{42}$ According to the organization data (Organization data section), drafting this part of the BP requires a preliminary plan of the provisional operational activities associated with an estimate of the number of samples that will be the subject of the different tasks. Before drafting a BP, it is also necessary to set an access policy and to adopt a cost recovery model. So far, many different economic models have been proposed and depending on the specific features of the biobank, caution is needed in making the choice. ${ }^{4,8,24,43-46}$

The first part of the financial provisions comprises the list of costs and a detailed analysis of each expense that a biobank will need to sustain its operational activities, broken down into individual cost categories. The yearly financial needs of the biobank are calculated from the sum of the total costs of each subcategory.

The second part of financial provision relates to funds. Funds represent the sustaining channels for all biobanks. They include all the money collected from private and public channels, which is provided to the institution to aid the operational activity of the biobank.

Revenues are the subject of the third part of financial provisions. Revenues raised by a biobank by providing different kind of services using the samples stored are reported in the Project description and mission section. The revenues will depend on the financial model adopted by the biobank. For each model, it implies a cost recovery (full, 
partial, marginal $)^{4,8,24,45,46}$; a systematic table reporting individual biospecimen/service costs to the user must be added to this BP section.

$\mathrm{BP}$ projections are calculated on a yearly basis. However, from a temporal point of view, the $\mathrm{BP}$ is structured in the medium to long term, usually no longer than 5 years ${ }^{17}$ and possibly with a greater level of detail for the initial years. The time horizon should not be longer than 5 years because after that period, every forecast could be unreliable. The same considerations apply to the timeline of a biobank BP, unless the specific situation suggests otherwise.

It is likely that for each year of the time horizon considered, the economic and financial projections will be different and will vary in the different stages (i.e., setting, initial, consolidated, scaling-up phase) of the biobank life and/or changes in marketing strategies and policies.

Costs. Costs represent the core of the BP. The section contains the estimates of each expenditure category that the biobank expects to incur over the next few years for its operating activities. The costs may be different for well-established biobanks and newly established ones, which will need to provide the investment to enable the infrastructure to operate.

The main cost categories that can be considered in the case of a biobank are the following:

(1) Human resources

(2) Laboratory instruments

(3) Research programs

(4) Network costs

(5) Marketing costs

(6) Quality

(7) Safety

As a facilitating tool for drafting the biobank's BP, Table 1 represents an example of most of the cost categories that need to be considered over 1 year.

As there is great heterogeneity in scope, methodologies, typology, structure, size, and governance in biobanking, the tables proposed in these articles of necessity are basic simplified schemas to enable the reader to become familiar with BP drafting. What is reported in each of these tables will depend on specific features of the biobank and complexity of activities/services of the infrastructure. With increasing complexity, the main tables regarding cost, funds, and revenues may be complemented with several other ancillary tables that break each category down into more individual subcategories.

Financial requirements of the biobank are represented by the sum of the total cost for each subcategory of expenses (Table 1).

Human resource costs. The payment of biobank personnel represents the costliest category in any system. A number of professional figures with different educational backgrounds may be required: biologists, physicians, laboratory technicians, bioinformatic scientists, administrators, bioethicists, as well as engineers, lawyers, and economists, who will be variously designated to cover the roles, for example, of biobank manager, quality manager, data manager, researcher, technician, information and technology experts, biosafety and biosecurity officer, secretarial staff, and legal and economic consultants.

In many cases, for small- and medium-sized biobanks, several functions may be covered by the same person, and the personnel working in the biobank will cover most of the ordinary daily operational activities, while consultants will be used to cover time-limited specific competencies.

Training and updating of personnel are an essential part of human resource management and integral to the activities expected to be implemented. Any cost for personnel updates and specific education, either from intramural or extramural sources, has to be taken into account in this section.

Laboratory instruments and services. Laboratory apparatus necessary to process and store biospecimens is another essential cost. This category should also take into account the average estimated life of an instrument to plan the gradual replacement of machinery. Equipment may be purchased, rented, or leased.

The category of laboratory instruments can be broken down into several subcategories as follows:

(a) Storage sample equipment. These include any instrument that allows the storage of samples at well-controlled temperatures.

(b) Laboratory. Equipment for sample handling may be limited simply to aliquoting or it may include a number of more complex activities (i.e., tissue handling; cell culture establishment; extractions and purification robotic/automatic sample management machines).

(c) Raw materials. This subcategory includes the costs for the acquisition of raw materials, for instance, gases, chemicals, disposables, and analytical commercial kits necessary for operation of the biobank. , $^{4,43}$

(d) Office equipment (i.e., chairs, desks, stationery, lamps, and telephones).

(e) IT equipment. Data management systems and the cost for their updating is an essential activity of the biobank.

(f) Service costs. This subcategory includes the expenses related to the services used by the biobank to perform its activities (i.e., electricity and water consumption; sample transport, special waste disposal). Building rents and/or loan costs for the facility are included in this subcategory if the biobank does not own the buildings where it operates. The section should also take into account the institutional/ administrative overhead costs charged to the biobank.

(g) Maintenance. Costs for contracts, which guarantee ordinary and extraordinary maintenance of any equipment, and for biosafety and biosecurity legal requirements are included here.

Research programs. An important source of sustainability for biobanks is partnership in research projects founded by either private or public bodies, which, however, may require additional costs.

Network and memberships. Each biobank may take advantage of networking and/or partnership with other biobanks or other complementary institutions or in membership of scientific societies. The expenses for such collaborations should be listed in this subsection.

Marketing costs. The costs for implementation of marketing strategies (see the Marketing strategies section above), including website setting and updating, as well as travel costs either for advertising/stakeholder meetings or fund raising, must also be taken into account in this category.

Quality certification. To increase reliability and confidence in the samples and services implemented, the biobank may 
Table 1. Biobank's Business Plan: Model Example for Cost Categories/Year

\begin{tabular}{|c|c|c|c|c|c|}
\hline \multicolumn{2}{|r|}{ COSTS } & \multicolumn{4}{|c|}{ TIME COVERAGE } \\
\hline \multirow[t]{2}{*}{ CATEGORIES } & \multirow[t]{2}{*}{ SUB CATEGORIES } & \multicolumn{4}{|c|}{ Year 1* } \\
\hline & & $\begin{array}{c}n . \\
\text { employee }\end{array}$ & $\begin{array}{l}\text { hours of } \\
\text { work/year }\end{array}$ & hour/cost & total cost \\
\hline \multirow{4}{*}{ 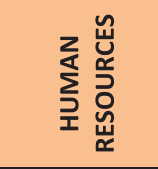 } & Personnel Typology (i.e. Technician) & & & & \\
\hline & Personnel Typology (i.e.: Quality manager) & & & & \\
\hline & Personnel Typology ... & & & & \\
\hline & Training & & & & \\
\hline \multirow{22}{*}{ 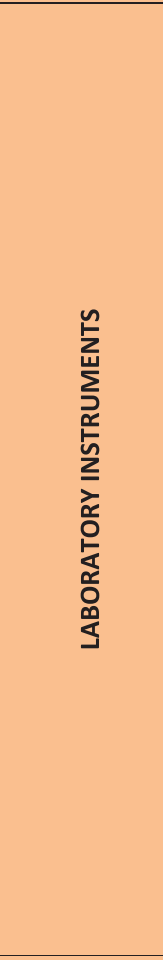 } & STORAGE SAMPLE EQUIPMENT & n. unit & \multicolumn{2}{|c|}{ cost } & total cost \\
\hline & Storage equipment (i.e. nitrogen thank) & & & \\
\hline & Storage equipment (i.e.: freezer) & & & \\
\hline & Storage equipment .. & & & & \\
\hline & LABORATORY EQUIPMENT & n. unit & \multicolumn{2}{|c|}{ cost } & total cost \\
\hline & Laboratory instrument (i.e: Centrifuge) & & & \\
\hline & Laboratory instrument.. & & \multirow{2}{*}{\multicolumn{2}{|c|}{ cost }} & \\
\hline & RAW MATERIALS & n. unit & & & total cost \\
\hline & Raw material (i.e. Gases, Kits) & & & \\
\hline & Raw material (i.e:. disposables,).. & & & \\
\hline & OFFICE EQUIPMENT & & & \\
\hline & Office equipment (i.e.: Stationery) & & & \\
\hline & Office equipment.. & & \multirow{2}{*}{\multicolumn{2}{|c|}{ cost }} & \\
\hline & IT EQUIPMENT & n. unit & & & total cost \\
\hline & IT equipment (i.e: Computers) & & & \\
\hline & IT equipment.. & & & & \\
\hline & SERVICE COSTS & & \multicolumn{2}{|c|}{ cost } & \\
\hline & \multicolumn{5}{|l|}{ Service cost (i.e.: electricity) } \\
\hline & Service cost (i.e: institutional /administrative overhead) & & & & \\
\hline & MAINTENANCE & description & n. unit & cost & total cost \\
\hline & Ordinary maintenance .. & & & & \\
\hline & ExtraOrdinary maintenance ... & & & & \\
\hline \multirow{4}{*}{ 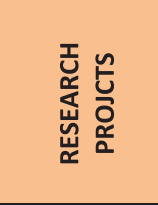 } & & \multicolumn{3}{|c|}{ cost } & total cost \\
\hline & Project research 1 (i.e: title, internal identifier..) & & & & \\
\hline & Project research 2 (i.e: title, internal identifier..) & & & & \\
\hline & $\begin{array}{l}\text { Fund raising cost (i.e: call identification, consortium } \\
\text { building etc..) }\end{array}$ & & & & \\
\hline & & & fee & & total cost \\
\hline$\sum_{3}^{\circ}$ & Network Participation (i.e.: fees) & & & & \\
\hline 喓 U & $\begin{array}{c}\text { Network Participation (i.e.: travel cost, } \\
\text { communication platforms..) }\end{array}$ & & & & \\
\hline 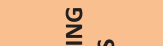 & & & cost & & total cost \\
\hline 点 & Marketing strategies (i.e.: Web site, publication..) & & & & \\
\hline$\sum$ & Marketing strategy... & & & & \\
\hline$\succeq$ & & & cost & & total cost \\
\hline$\frac{1}{5}$ & Quality (i.e: Quality control program / Proficiency test) & & & & \\
\hline$\widetilde{\sigma}$ & Quality (i.e: Accreditation/ Third part certification, QMS) & & & & \\
\hline SAFETY / & & & cost & & total cost \\
\hline SAFEIT/ & Safety (i.e: risk assessment /contingency plan..) & & & & \\
\hline & Safety (i.e: disaster recovery...) & & & & \\
\hline & Total Cost (Financi & I NEED) $* *$ & & & \\
\hline
\end{tabular}

According to the activities, each category listed in the first column has to be broken down into individual subcategories that are reported in the second column. The following columns contain the indicators necessary to calculate the estimated total cost listed in the last column. For each cost category, a few indicative examples are indicated.

*To complete for the following years covered by the BP. ${ }^{17}$

**Financial need: the sum of each cost reported in the last column is the provision of yearly total expenditure.

$\mathrm{BP}$, business plan; QMS, quality management system. 
Table 2. Biobank's Business Plan: Model Example for Revenue Category/Year

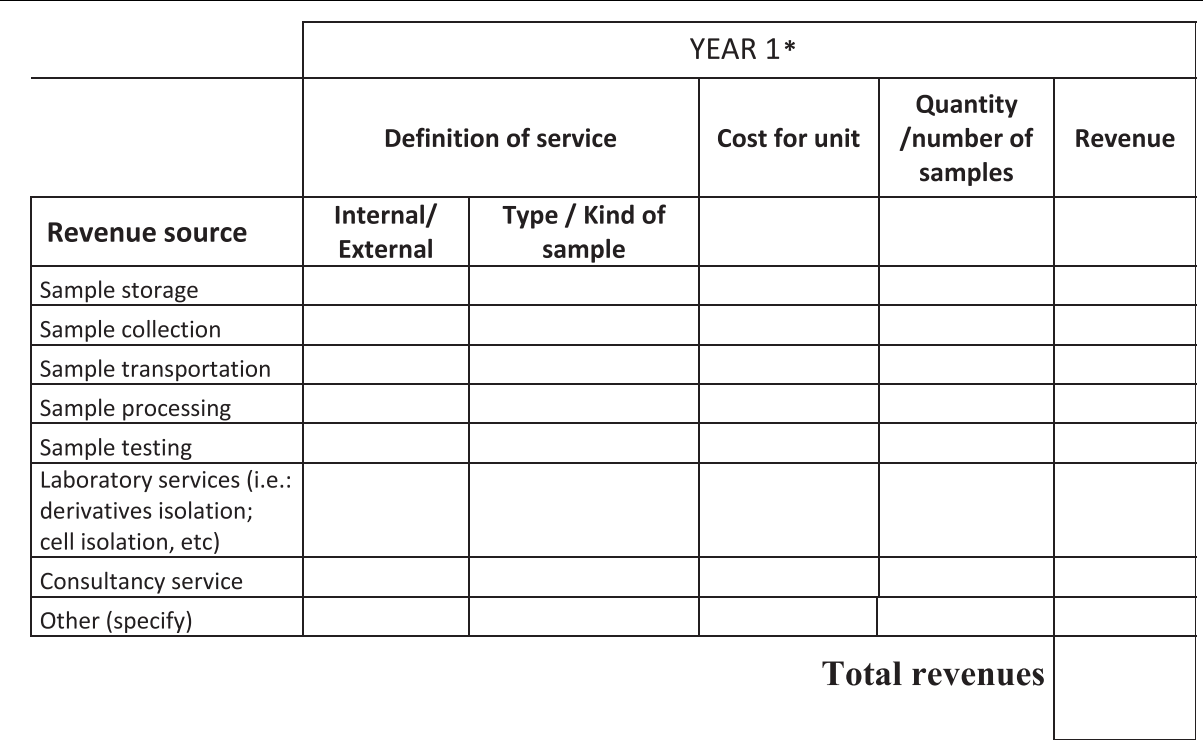

The Table shows a simplified schema to report the biobank revenues derived from cost recovery of the services/samples delivered. Individual cost for each source has to be preliminarily defined by the biobank.

The first column lists the types of services that are provided by the biobank.

The second column differentiates services delivered in response to internal or external demand.

The third column describes the type of service or the kind of samples/object of the request.

The fourth column indicates the cost for unit of services or for single sample used to provide the service. The following column contains indication on quantitation of services or the number of samples used to provide the service. The last column reports the total revenue gained by the biobank for the related service.

*The schema must be filled for each of the following years covered by the BP. ${ }^{17}$

join specific biospecimen proficiency testing, ${ }^{47}$ quality control programs, and/or comply with the requirements for Accreditation and Certification Programs. ${ }^{48}$ The cost for implementation of the appropriate QMS should also be taken into consideration here. ${ }^{24}$

Revenues. Biobanks, especially public biomedical entities, are institutions created to improve health and are devoted to providing services for the public good, thus they are not expected to generate revenues. ${ }^{4}$ However, the funds collected are often not sufficient to guarantee financial sustainability of the biobank. For this reason, biobanks need to implement a cost recovery process, and this implies the payment of a fee for the services they offer. It has been estimated in a study by the International Society for Biological and Environmental Repositories on 15 different types of biobanks that revenue flows generated with the application of a cost recovery policy ${ }^{4}$ raise only $25 \%$ of the costs sustained and that it is unlikely that biobank financial sustainability can be totally achieved only with this policy. ${ }^{49}$

Table 3. Biobank's Business Plan: Model Example for Fund Categories/Year

\begin{tabular}{|c|c|c|c|}
\hline & \multicolumn{3}{|c|}{ YEAR 1* } \\
\hline Fund Sources & \multirow{8}{*}{$\begin{array}{c}\text { Financial } \\
\text { Need } * *\end{array}$} & $\begin{array}{l}\text { Amount } \\
\text { collected }\end{array}$ & $\begin{array}{c}\text { Percentage } \\
\text { covered }\end{array}$ \\
\hline Funding by research grants & & & \\
\hline Funding by the host institution & & & \\
\hline Philanthropic donations & & & \\
\hline Private venture capital & & & \\
\hline Public funding & & & \\
\hline Total Revenues*** & & & \\
\hline Other (specify) & & & \\
\hline
\end{tabular}

The financial sources available to a biobank are listed in the first column. The second column contains an indication of the total amount needed by the biobank to cover its costs during the year. In the third column, the amounts collected by the biobank using the different sources indicated in the first column. The last column reports the proportion of the total amount financed by each fund, in percentage terms.

*The schema must be filled for each of the following years covered by the BP. ${ }^{17}$

**Financial need derived from Table 1.

***Total revenues derived from Table 1 . 
Costs for services vary and are based on either partial or total cost recovery. ${ }^{4,8,45,49}$ Often the price reflects the users' willingness to pay, which means that the price is set by the market. ${ }^{50}$

Specific competencies (i.e., ethical, cryotechnology, legal) may become a source of revenue in terms of consultancy. However, more often, biobank delivers services related to biological material such as access, storage, collection, transportation, processing, testing of samples, and data management. ${ }^{4,19,43}$ Biospecimens and their derivatives are released by biobanks for public or private use ${ }^{38,51}$ without charge or with a cost established for each individual bioresource made available. ${ }^{4,5}$ Table 2 represents a simplified facilitating tool for the biobank to report its revenue channels. As specified above, the table does not intend to be exhaustive as each biobank defines this table in agreement with the cost recovery model adopted.

Funds. Possible financing channels for biobanks in addition to revenues are philanthropic donations, grants, research project funding, budgets from the host institution, and, more often, a variable mixture of all of these. . $20,38,51^{\prime}$

Public funding is highly dependent on the host institution and country.

Research grants may also represent a primary support for biobanks. ${ }^{5}$ Grants refer to the funds received by the biobank from institutions as nonrepayable money. The biobank may be an active participant in research projects financed by local, regional, national, or international institutions. Sometimes, when the biobank is incorporated into a hospital/ institution, part of the funds (corporate budget) of the host organization are dedicated to the biobank also in the form of research grants.

Philanthropic donations are the funds collected from private citizens who want to finance the structure directly or using not-for-profit organizations created on an ad hoc basis to support the biobank. ${ }^{19,20}$

Each type of funding, alone or in combinations of varying proportions, will contribute to the sustainability of a biobank. Table 3 represents a facilitating tool the biobank can use to define its per annum financial needs, and it should be repeated for each year of the time horizon considered in the BP.

\section{Conclusion}

Economic and financial sustainability represents a major challenge for the survival of a biobank. Too often, the management of public health institutions is undertaken without an economic approach, and this may affect their long-term sustainability. Although this concept is becoming recognized as important in biobanking, there is still scarce familiarity and knowledge of basic principles for drafting and implementing a useful and strategic BP. ${ }^{12,16,45}$

The primary purpose of this article is to facilitate communication between biobanker scientists and economists and to assist with familiarization of BPs, which are instruments created in the economic world that favor long-term sustainability of companies. In fact, the BP lays out the future evolution of the biobank mission, it shows costs and revenues, and represents the best managerial tool to achieve the longterm targets and to preserve the interests of all the stakeholders $^{33}$ involved in the biobanking process. Its ultimate purpose is to call for rethinking the organization of biobanks to successfully ensure their sustainability in the long term.

\section{Acknowledgments}

The authors are grateful to Prof. K.M. Botham for language revision of manuscript and helpful advice on the final manuscript. The work was supported by the Italian Ministry of Health and the Ministry of Education, University and Research.

\section{Author Disclosure Statement}

No conflicting financial interests exist.

\section{References}

1. OECD. Statistical definition of biotechnology. Available at www.oecd.org/sti/biotech/statisticaldefinitionofbiotechnology .html (accessed September 20, 2016).

2. Douglas CMV, Scheltens P. Rethinking biobanking and translational medicine in the Netherlands: How the research process stands to matter for patient care. Eur J Hum Genet 2015;23:736-738.

3. Marko-Varga G. BioBanking as the central tool for translational medicine CTM issue. Clin Transl Med 2013;2:4.

4. Clement B, Yuille M, Zaltoukal K, et al. Public biobanks: Calculation and recovery of cost. Sci Transl Med 2014;6: $261 \mathrm{fs} 45$.

5. Simeon-Dubach D, Henderson MK. Sustainability in biobanking. Biopreserv Biobank 2014;12:287-291.

6. Campos AH, Schreeder M, Parry-Jones A, et al. Addressing the challenge of financial sustainability in biobanking. Biopreserv Biobank 2015;13:387-395.

7. Recommendation $\mathrm{CM} / \operatorname{Rec}(2016) 6$ of the Committee of Ministers to member States on research on biological materials of human origin. Available at: https://search.coe.int/ $\mathrm{cm} /$ Pages/result_details.aspx ?ObjectId=090000168064e8ff (accessed September 20, 2016).

8. Gonzalez-Sanchez MB, Lopez-Valeiras E, Morente MM, Fernandez Lago O. Cost model for biobanks. Biopreserv Biobank 2013;11:272-277.

9. Stutely R. Il Business Plan. Financial Times Prentice Hall. 2007;89-128. Available at www.rumahstudio.com/kuliah/rbti/ _Marketing/The\%20Definitive\%20Business\%20plan.PDF (accessed September 20, 2016).

10. Karlsson T, Honig B. Judging a business by its cover: An institutional perspective on new ventures and the business plan. J Bus Ventur 2009;24:27-45.

11. Brinckmann J, Grichnik D, Kapsa D. Should entrepreneurs plan or just storm the castle? A meta-analysis on contextual factors impacting the business planning-performance relationship in small firms. J Bus Ventur 2008;25:24-40.

12. Sahlman WA. How to write a great Business Plan. Harvard Bus Rev 1997;75:98-108.

13. Mabile L, Dalglaish R, Thorisson GA, et al. Quantifying the use of bioresources for promoting their sharing in scientific research. GigaScience 2013;2:7.

14. Harris JR, Burton P, Knoppers BM, et al. Toward a roadmap in global biobanking for health. Eur J Hum Genet 2012;20:1105-1111.

15. Wichmann HE, Kuhn KA, Waldenberger M, et al. Comprehensive catalog of European biobanks. Nat Biotechnol 2011;29:795-797.

16. Henderson M, Simeon-Dubach D, Monique A. Finding the path to biobank sustainability through sound business planning. Biopreserv Biobank 2015;13:385-386.

17. Schneider JE. The way to a powerful business plan. Drug Discov Today 2002;7:342-345. 
18. Bravo E, Calzolari A, De Castro P, et al. Developing a guideline to standardize the citation of bioresources in journal articles (CoBRA). BMC Med 2015;13:33.

19. Simeon-Dubach D, Watson P. Biobanking 3.0: Evidence based and customer focused biobanking. Clin Biotech 2014; 47:300-308.

20. Bromley RL. Financial stability in biobanking: Unique challenges for disease-focused foundations and patient advocacy organizations. Biopreserv Biobank 2014;12:294-299.

21. Baird PM, Frome RJ. Large-scale repository design. Cell Preserv Technol 2006;3:256-266.

22. OECD Best Practise Guidelines 2007. Available at www .oecd.org/sti/biotech/38777417.pdf (accessed September 20, 2016).

23. Johnson G, Scholes K, Sexty R. Exploring Strategic Management. Scarborough, Ontario, Canada: Prentice Hall; 1989: 69.

24. Bravo E. Biotecnologie: Nuove risposte ai problemi esistenti e alle sfide future. U\&C 2015;7:29.

25. Vaught J, Rogers J, Carolin T, Compton C. Biobankonomics: Developing a sustainable business model approach for the formation of human tissue biobank. J Natl Cancer Inst Monogr 2011;42:24-31.

26. Federer LM, Lu YL, Joubert DJ, Welsh J, Brandys B. Biomedical data sharing and reuse: Attitudes and practices of clinical and scientific research staff. PLoS One 2015; 10:e0129506.

27. Simeon-Dubach D, Zaayenga A, Henderson MK. Disaster and recovery: The importance of risk assessment and contingency planning for biobanks. Biopreserv Biobank 2013; 11:133-134.

28. Hager R. Biobanking operations: Contingency planning and disaster recovery of research samples. BioProcess $\mathrm{J}$ 2014;13:56-58.

29. Baird PM, Benes FM, Chan CH, et al. How is your biobank handling disaster recovery efforts? Biopreserv Biobank 2013;11:194-201.

30. Bart CK, Bontis N, Taggar S. A model of the impact of mission statements on firm performance. Manage Decision 2001;39:19-35.

31. Stallworth Williams L. The mission statement: A corporate reporting tool with a past, present, and future. J Bus Comm 2008;45:94-119.

32. Freeman ER. Strategic Management: A Stakeholder Approach. Cambridge: Cambridge University Press; 1984: 126-152.

33. Bjugn R, Casati B. Stakeholder analysis: A useful tool for biobank planning. Biopreserv Biobank 2012;10:239-244.

34. Shaw DM, Elger BS, Colledge F. What is a biobank? Differing definitions among biobank stakeholders. Clin Genet 2014;85:223-227.

35. Mitchell D, Geissler J, Parry-Jones A, et al. Biobanking from the patient perspective. Res Involvem Engagem 2015;1:4.

36. Wallace S, Knoppers BM. The role of P3G in encouraging public trust in biobanks. In: Dabrock P, Taupitz J, Ried J (eds). Trust in Biobanking. Dealing with Ethical, Legal and Social Issues in an Emerging Field of Biotechnology. Berlin, Heidelberg: Springer-Verlag.

37. Kotler P, Armstrong GG. Principi di Marketing. Pearson Educational Italia (Milano), 11th Edition 2006: 215-552.

38. Zika E, Papatryfon I, Wolf O, et al. Consequences, Opportunities and Challenges of Biotechnology for Europe.
2007: 22-114. Available at: http://ftp.jrc.es/EURdoc/eur22 728en.pdf (accessed June 2015).

39. Daft RL. Organization Theory and Design, 2nd edition. Mason, USA: South-Western Cengage Learning. 2013: 75-115.

40. Boundless Management. Functional Structure. Available at www.boundless.com/management/functional-structure-1463979 (accessed June 15, 2016).

41. Hopt KJ, Leyens PC. Board Models in Europe-Recent developments of internal corporate governance structures in Germany, the United Kingdom, France, and Italy. Eur Company Financ Law Rev 2004;18:135-168.

42. Odeh H, Miranda L, Rao A, et al. The Biobank Economic Modeling Tool (BEMT): Online Financial Planning to Facilitate Biobank Sustainability. Biopreserv Biobank 2015;13:421-429.

43. Wilson GD, D'Angelo K, Pruetz BL, et al. The challenge of sustaining a hospital-based biobank and core molecular laboratory: The Beaumont experience. Biopreserv Biobank 2014;12:306-311.

44. Barbareschi M, Cotrupi S, Guarrera GM. Biobanca: Strumentazione, personale e analisi dei costi. Pathologica 2008; 100:139-143.

45. Warth R, Perren A. Construction of a business model to assure financial sustainability of biobanks. Biopreserv Biobank 2014;12:381-389.

46. Albert M, Bartlett J, Johnston RN, Schacter B, Watson P. Biobank bootstrapping: Is biobank sustainability possible through cost recovery? Biopreserv Biobank 2014;12:374380.

47. ISBER Biospecimen Science Working Group. Biorepository proficiency testing for the quality control of biospecimens for the global biobanking community. Biopreserv Biobank 2011;9:415-417.

48. Matzke EA, O'Donoghue S, Barnes RO, et al. Certification for Biobanks: The program developed by the Canadian Tumour Repository Network (CTRNet). Biopreserv Biobank 2012;10:426-432.

49. Vaught J, Rogers J, Myers K, et al. An NCI perspective on creating sustainable biospecimen resources. J Natl Cancer Inst Monogr 2011;42:1-7.

50. Pharma Report. 2015. Biobanking for medicine: Technology, industry and market 2015-2025. Available at www.vision gain.com/Report/1455/Biobanking-for-Medicine-TechnologyIndustry-and-Market-2015-2025 (accessed June 15, 2016).

51. Gee S, Georghiou L, Oliver R, Yuille M. 2013. Financing UK biobanks: Rationale for a National Biobanking Research Infrastructure. Available at www.stratumbiobanking .org/docs/STRATUM\%20COST\%20MODEL\%20FINAL\% 20REPORT\%20MAY\%202013.pdf (accessed June 15, 2016).

Address correspondence to:

Elena Bravo, BD

Departments of Haematology, Oncology and Molecular Medicine

Istituto Superiore di Sanità Viale Regina Elena, 299

Rome 00186

Italy

E-mail: elena.bravo@iss.it 